\title{
A crise financeira corrente, suas causas e suas soluções numa perspectiva inspirada em Keynes e Minsky
}

Fabiano A. S. Dalto*

RESUMO - A nota parte da abordagem da instabilidade financeira inspirada em Keynes e Minsky para avaliar a crise financeira iniciada no mercado imobiliário americano e espalhada pelo mundo. A nota argumenta que a crise desenvolveu-se como um resultado endógeno do funcionamento dos mercados numa economia capitalista. Junto a isso, políticas neoliberais contribuíram para a gravidade da crise na medida em que negligenciaram as consequências distributivas de suas políticas que, junto com a leniência regulatória e as inovações predatórias que tais políticas incentivaram, alimentaram o endividamento de devedores altamente arriscados. Como sugeriram Keynes e Minsky, o capitalismo tende a produzir desigualdade e desemprego e ambos nutrem sua instabilidade. Argumenta-se que uma resolução progressista desta crise, necessita de reformas estruturais baseadas em pelo menos três princípios: a) criação de emprego pagando salários decentes; b) aumento do investimento público em infraestrutura e em serviços que têm efeitos positivos sobre as condições de vida dos mais pobres; c) e socialização dos investimentos públicos com reformas que ampliem o controle da sociedade sobre as atividades do estado e do setor privado e aumentem a participação da sociedade civil nos centros de decisão das políticas do estado.

Palavras-chave: Keynes. Minsky. Instabilidade financeira. Crise financeira. Distribuição de renda. Desemprego. Socialização do investimento.

\section{INTRODUÇÃO}

Eis que revivemos um momento Keynesiano. Diante da crise financeira e de suas consequências sobre a "economia real", todos parecemos keynesianos agora e clamamos pela intervenção saneadora do governo. Em termos gerais, herdeiros de Keynes apoiam, como funções estabilizadoras em tempos de crise, o papel do Estado como emprestador de última instância (Banco Central) aos bancos e empresas problemáticos e como gerador da demanda efetiva compensatória, por meio do déficit público, da redução dos gastos (por temor ou por incapacidade) do setor privado. Banqueiros, antes reticentes em relação às intervenções do governo e convictos da incompetência pública em gerenciar honesta e eficientemente a economia, hoje clamam por mais intervenções estatais para salvá-los de sua imprudência, incompetência e improbidade. O gasto e a dívida públicos, antes vistos como pai e mãe, respectivamente, de todos os males, são exortados como tábuas de salvação contra o derretimento do capital financeiro e as falências de indústrias sem mercados e lucros (onde foi parar a responsabilidade fiscal quando precisamos dela?!). Assim, banqueiros e industriais

\footnotetext{
* Doutor em Economia pela Universidade de Hertfordshire. É professor adjunto do Departamento de Economia da Universidade Federal do Paraná. Endereço eletrônico: dalto@ufpr.br.
} 
agora parecem mais com os keynesianos do que antes da crise, quando apoiaram o neoliberalismo em sua cruzada pela desregulação e pela liberalização dos mercados, pela privatização das atividades públicas e pela mercantilização de tudo que não fosse ainda comercializável. Enquanto, em termos gerais, não há dúvida quanto à necessidade de intervenções saneadoras do Estado, argumentamos que é preciso avaliar as causas da instabilidade financeira para informar os detalhes dessas intervenções, com o intuito de não só impor os custos das intervenções aos que produziram a crise como também de implementar políticas e reformas que reduzam a probabilidade de crises dessa magnitude no futuro.

Este artigo é inspirado na tradição keynesiana e traz ao debate questões centrais dessa teoria que têm sido esquecidas ou negligenciadas na maior parte das discussões diárias sobre a crise. Primeiramente, lembramos que Keynes (1964, cap.24) entendia que o capitalismo possui dois problemas centrais em sua gênese: de um lado, a tendência de manter níveis de emprego abaixo de sua plena capacidade produtiva e, de outro, a tendência de produzir desigualdade na distribuição de renda e de riqueza. Ambos, obviamente, conectamse. Mais do que apenas evitar a destruição de instituições financeiras e industriais, as políticas públicas deveriam ser orientadas no sentido de solucionar esses dois males em conjunto. Hyman Minsky (1986) por sua vez, seguiu Keynes para desenvolver sua teoria da instabilidade financeira, argumentando que tal instabilidade é, intrinsecamente, resultado do modo como o sistema capitalista funciona. Mais do que mudanças marginais nas políticas monetária e fiscal, Minsky (op. cit., cap.12) propunha que a economia precisava de mudanças profundas nas instituições básicas do capitalismo, em particular, nas que regulam a distribuição de renda e de riqueza, se a instabilidade era para ser evitada. Além disso, os desenvolvimentos que levaram à crise atual e agora as próprias medidas de sua contenção têm mostrado a relação problemática, mesmo promíscua, entre o Estado e os agentes privados. Assim, a crise clama não só pelas políticas estabilizadoras de renda inspiradas em Keynes e Minsky, mas, exige, também, maior democratização nas esferas de decisão pública e privada. Na linha minskyana de reformas fundamentais das instituições que regulam o processo decisório, as reformas propostas para resolução da crise atual também devem contemplar uma maior participação das comunidades, dos trabalhadores, das mulheres, etc., nos processos decisórios público e privado. Dado o enorme volume de recursos públicos que está sendo e que deverá ser aplicado diretamente pelo governo ou transferido para agentes privados, deve-se exigir, por 
certo, a responsabilização diante da sociedade de entes públicos e especialmente de privados usuários ou beneficiários desses recursos.

$\mathrm{Na}$ análise que se segue, assinalamos o papel da desigualdade de renda na geração da instabilidade financeira das economias americana e mundial e alertamos para os riscos de agravamento das deficiências estruturais do capitalismo identificadas por Keynes e por Minsky se, no conjunto de políticas tomadas para resolver a crise atual, não se priorizar mudanças institucionais que impliquem em geração de empregos com distribuição de renda. Argumentamos, ainda, que enquanto as políticas públicas de gasto, de redução de impostos e de concessão de crédito ao setor privado financeiro e não-financeiro precisam ser orientadas para atingir o pleno emprego, reformas institucionais profundas precisam ser implementadas para redistribuir o poder de decisão entre os diversos setores da sociedade e para melhorar a distribuição de renda e de riqueza. Ou seja, sugere-se que o problema macroeconômico do desemprego e da desigualdade precisa de uma política pública dedicada diretamente a solucioná-lo, concomitantemente com uma reformulação do arcabouço institucional em que as decisões são tomadas, se os custos da atual crise financeira são para ser pagos por seus criadores e os de novas crises evitados ou reduzidos. A análise se concentrará no desenvolvimento da crise financeira nos EUA, mas, traçará, também, conclusões gerais que, pretende-se, são aplicáveis ao Brasil.

\section{IDEOLOGIA, POLÍTICA E TEORIA}

A ideologia neoliberal, que domina a cena econômica de países desenvolvidos e subdesenvolvidos há mais de 30 anos, tem produzido uma série de políticas que hoje são contestadas pela crise financeira internacional. Se é certo que em cada país a ideologia neoliberal encontra formatos próprios, merecedores de análise específica, também é certo que se funda em princípios norteadores gerais, cuja uniformidade de valores podemos identificar. De forma geral, a ideologia neoliberal baseou-se na ideia de que os indivíduos sabem o que é melhor para si mesmos e no preceito de que o livre mercado é o melhor ambiente para liberar as forças progressivas em cada um dos indivíduos, ao prover os incentivos econômicos que os levaria a adotarem as práticas econômicas mais eficientes para si e, de modo espontâneo e sem intenção, para toda a sociedade. O Estado, na perspectiva neoliberal, é, no mais das vezes, prejudicial, introduz distorções ao sistema de preços, engendra atividades rent seeking e 
deveria ser limitado a funções econômicas de investimento em infra-estrutura, em segurança, em justiça e em defesa do território. ${ }^{8}$

Como quer que seja, foi pelo açodamento dessa ideologia que governos de países desenvolvidos e subdesenvolvidos, desde 1980, se renderam às políticas denominadas "pró mercado". Mesmo keynesianos de velha cepa concordaram com aqueles princípios." Liberalização, privatização e desregulação dos mercados financeiros e flexibilização do mercado de trabalho foram implementadas. Isso tem introduzido o que James Crotty (2002) chamou de modelo de fraca demanda efetiva com coercitiva competição - em linhas gerais: alta competição, redução dos salários, "curto prazismo" e financeirização. Argumentamos que esses elementos, combinados, alimentaram a instabilização financeira que levou a crise atual.

A teoria convencional acreditava e fazia crer, pelo menos até a crise atual, que os mercados funcionam eficientemente. De modo específico, mercados financeiros eficientes permitem alocação eficiente de recursos para aqueles setores de maior retorno, isto é, transferindo riscos para aqueles que querem e podem suportá-los. Keynes, ao contrário, alertava recorrentemente para a instabilidade inerente de uma economia monetária, cuja criação de renda e de riqueza é comandada por decisões de investimentos descentralizadas e em condições de incerteza (Keynes 1964, cap.12, para exemplificar). Em tais condições, assinalava Keynes, uma economia comandada apenas pelas forças de mercado e pelo animal spirit de capitalistas está sujeita a flutuações consideráveis em seu nível de atividade e opera, em geral, abaixo de sua capacidade de pleno uso das forças produtivas. Na visão de Keynes (op. cit., cap.24), para reduzir a instabilidade das economias capitalistas e os desperdícios de forças produtivas - representados pelo desemprego -, deve-se basear a geração de renda naquelas despesas mais estáveis em relação à renda corrente, vale dizer, no consumo; e naquelas sob controle social, isto é, os gastos do governo. A estabilidade do consumo, por seu turno, depende de uma distribuição de renda mais equitativa enquanto os gastos do governo deveria se pautar pela "socialização dos investimentos".

Voltemos rapidamente a Minsky. De acordo com ele, a instabilidade financeira emerge endogenamente da relativa estabilidade econômica que encoraja, por sua vez, a constituição de estruturas financeiras frágeis. Tal fragilidade deixa a economia à mercê de

\footnotetext{
8 Obviamente, todas essas exceções dão margem a vários questionamentos quanto à consistência dos preceitos neoliberais. Por exemplo: se o Estado é intrinsecamente ineficiente como querem os neoliberais, como poderia ser eficiente em áreas tão cruciais quanto justiça e segurança, ou, mesmo, para decidir seus investimentos em infraestrutura? Dependendo de como sejam definidas, defesa, segurança e justiça podem muito bem servir de justificativa para uma ampla esfera de intervenções do Estado, muito além do que parece ser o Estado mínimo neoliberal. Não é nossa intenção discutir essas e outras inúmeras inconsistências teóricas do neoliberalismo.

${ }^{9}$ É o caso, por exemplo, de Bresser-Pereira (1990, p.514).
} 
mudanças financeiras, tecnológicas ou políticas, para ilustrar, que afetam o retorno dos investimentos. Em momentos de estabilidade, os agentes em geral - banqueiros, empresários e famílias - estão dispostos a tomar mais riscos e diminuem as margens de segurança para concederem/tomarem empréstimos ou alavancarem gastos. Enquanto a economia vai bem, a avaliação da capacidade de pagamento das dívidas assumidas melhoram porque a maioria das firmas e dos consumidores estão obtendo renda suficiente para honrar seus compromissos correntes. Essa avaliação positiva não é fruto de euforia, nem de irracionalidade. É apenas comportamento convencional. Enquanto não há qualquer nova informação que abale esse estado de convenções, diria Keynes, não há porque mudarmos o curso de nossas ações. Uma vez sabendo que o futuro é incerto nos baseamos naquilo que conhecemos, ao invés de nos basearmos naquilo que não conhecemos ou conhecemos apenas vagamente. Na terminologia de Keynes, os agentes reduzem sua preferência pela liquidez e prosseguem tomando mais dívidas (ou concedendo mais créditos ou reduzindo o valor das garantias aceitas para concederem mais crédito, no caso dos financiadores) para financiarem seus gastos - ou gastos de terceiros, se for uma instituição financeira concedendo crédito.

Em certo momento, a redução das margens de segurança chega a um nível tal que qualquer frustração negativa das expectativas de renda esperada - ou crescimento de custos financeiros inesperados - pode levar a revisões dos planos de gastos das unidades produtivas, de consumo pelas famílias ou de financiamento por parte das unidades financeiras. Empresas e famílias não conseguem satisfazer dívidas assumidas no período de estabilidade e bancos não conseguem recuperar empréstimos concedidos. Empresas demitem; trabalhadores perdem emprego e renda e diminuem o consumo. Firmas e trabalhadores tornam-se inadimplentes e bancos cortam o financiamento para recuperarem seus níveis de liquidez. Agora, o histórico do repagamento do crédito concedido vai contra os tomadores. A nova convenção é de que não há bons pagadores. A demanda efetiva se reduz e com ela o nível de renda e de emprego, num efeito multiplicador às avessas. A convenção, agora, corre no sentido da recessão e todos os agentes aumentam ao mesmo tempo seu desejo pela liquidez.

Enquanto perdura a desconfiança, e a preferência pela liquidez estiver em alta, o setor privado não retoma as decisões de investimento, consumo e financiamento. Dado que o dinheiro estatal é, nas economias modernas, a liquidez por excelência, os bancos centrais são chamados a operar como emprestadores de última instância para evitarem a débâcle de seus associados do sistema financeiro. Os bancos podem recuperar suas margens de segurança com o socorro do Banco Central, mas, não recuperam a confiança de que seus devedores 
serão capazes de honrar suas dívidas. Dessa forma, a manutenção dos níveis de emprego e de renda necessita que o governo opere uma política fiscal de gastos que recupere os lucros e o nível de atividade econômica. Seja como emprestador de última instância, de um lado, seja com amplos déficits fiscais de outro, o governo, quando atua para estabilizar a economia, é chamado a retomar os níveis de gasto da economia e a estabilizar lucros.

\section{COMO CHEGAMOS ATÉ AQUI: AS CONSEQUÊNCIAS ECONÔMICAS DO MODELO “GERA E DISTRIBUI”}

Já não há mais dúvidas, mesmo entre adeptos dos mercados eficientes, que a crise financeira, iniciada no mercado imobiliário de segunda linha dos EUA, já se espalhou para toda a economia americana e a mundial. Os anúncios de desemprego em massa são catastróficos e não se restringem apenas ao setor financeiro. Só em fevereiro deste ano, o desemprego nos EUA chegou a 651 mil trabalhadores - 4,4 milhões desde dezembro de 2007, elevando a taxa para 8,1\%, maior taxa vista no país desde 1983. As taxas de desemprego na Europa subiram para o mesmo patamar $(8,2 \%)$ e o FMI prevê uma contração do produto mundial pela primeira vez em 60 anos. Piores ainda são as previsões dos efeitos dessa crise para as economias mais pobres da África e Ásia.

Não há dúvida, também, que parte das razões que levaram a essa crise se encontra nas políticas de liberalização e de desregulação dos mercados financeiros - sob a batuta neoliberal -, que estimularam as inovações financeiras dos derivativos mais exóticos até hoje conhecidos. Bancos, em concorrência com mercados de capitais desregulados e mais baratos, foram liberados para participar da securitização de dívidas e desenvolveram uma complexa rede de empréstimos transformados em títulos para revenda nos mercados de capitais. Tais empréstimos acabaram não aparecendo em seus balanços e seus riscos eram redistribuídos em uma longa cadeia de investidores desinformados (ou informados até demais). Dava-se início ao modelo "gera e distribui". O objetivo era o de fugir das exigências de capital mínimo, requerido dos bancos em proporção aos empréstimos, e permitir-lhes que alavancassem novos empréstimos. Como os créditos eram revendidos a terceiros, os lucros que os bancos poderiam auferir tornaram-se, nesse modelo, dependentes da quantidade de contratos de crédito que conseguissem fechar para redistribuir com ganhos de comissão. Agências de avaliação de riscos (ratings) faziam a classificação desses títulos derivados de créditos. A comissão obtida com a venda dos títulos era compartilhada com as agências das carteiras. Obviamente, as avaliações estavam contaminadas pelos próprios interesses das agências de avaliação de riscos e pela necessidade de seus clientes-sócios. 
Os vícios morais e éticos a que o modelo "gera e distribui" deu vazão foram bem mais explorados pela mídia do que outros elementos centrais em que se baseava o modelo. Independentemente da improbidade com que o sistema estava sendo gerido, a ideologia neoliberal de gestão da economia conspirava para o desenvolvimento do modelo mencionado acima. Mais especificamente, a outra parte componente do modelo "gera e distribui" envolveu a extensão do crédito para ampla massa de trabalhadores desempregados e para famílias empobrecidas. Isto é, como sugeriram Keynes e Minsky, a instabilidade capitalista, e a crise que atualmente assistimos, está fundamentalmente ligada à forma como o sistema financeiro opera e às tendências da economia capitalista em usar insuficientemente a capacidade produtiva disponível e em gerar desigual distribuição de renda.

GRÁFICO 1 - EUA: PARCELA DA RENDA DISPONÍVEL RECEBIDA PELO 1\% MAIS RICO -19132006

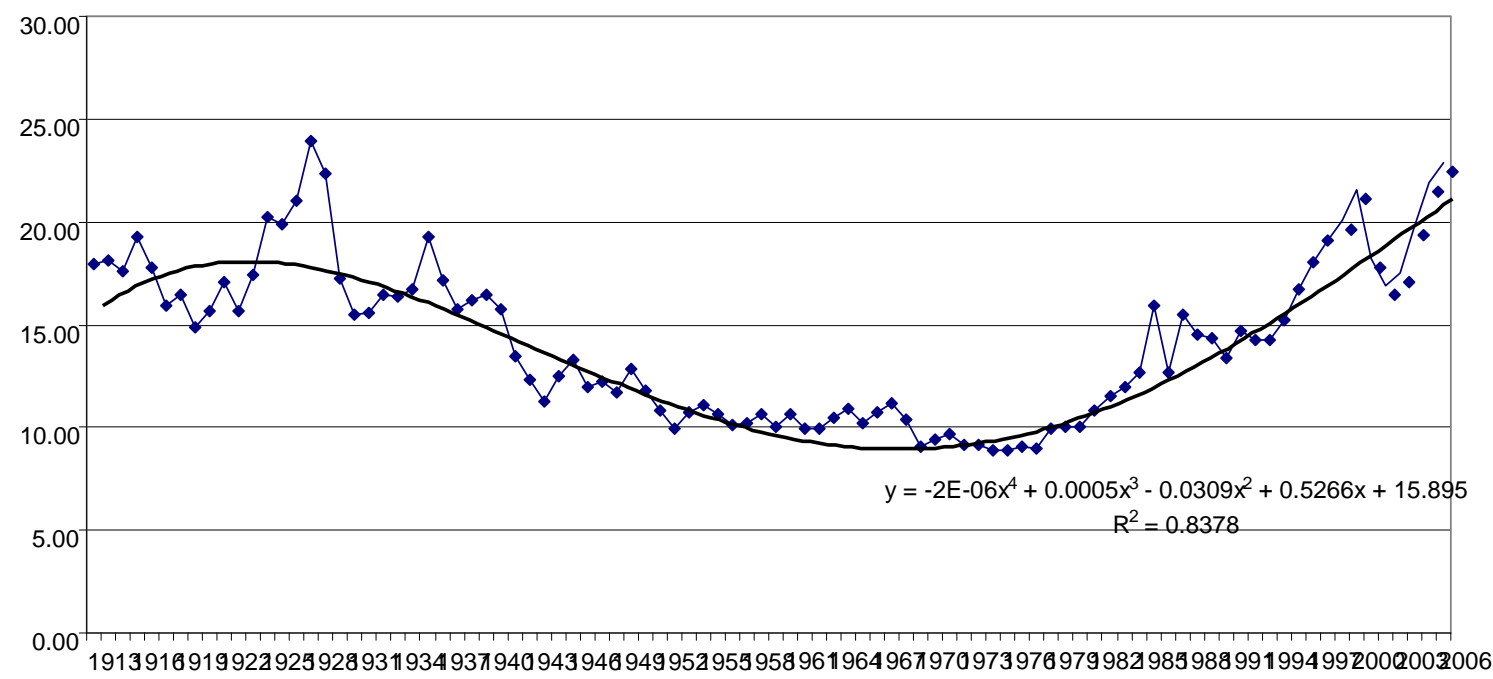

FONTE: Piketty, Thomas e Saez, Emmanuel "The Evolution of Top Incomes: A Historical and International Perspective", American Economic Review, Papers and Proceedings, 96(2), 2006, 200-205, com atualização até 2006 encontrada na página eletrônica: http://elsa.berkeley.edu/ saez/.

O Gráfico 1, acima, mostra a evolução da renda (incluindo salários, dividendos e juros) dos americanos mais ricos. Chama a atenção o nível de concentração de renda ocorrida desde a década de 1970, atingindo em 2006 o cume de 22,9\%. Não por acaso, apenas o nível de concentração de renda prevalecente na proximidade da crise de 1929 rivaliza com a de 2006. Entre o fim da Segunda Guerra Mundial e fins da década de 1960, há um extraordinário declínio na parcela de renda recebida pelos mais ricos e redução da desigualdade. Como se sabe, o pós-guerra foi um período não só de grande prosperidade, como, também, de relativa estabilidade no cenário da economia americana e da internacional. Já no período pós 1970, há um retrocesso na distribuição de renda nos EUA. Enquanto a renda do quintil mais pobre 
estagnou em termos reais entre 1979 (US\$ 15.965,00 a preços de 2007) e 2007 (US\$ 16.068,00 a preços de 2007), a dos 5\% mais ricos quase dobrou (passando de US\$ 181.955,00 em 1979 para US\$316.618,00 em 2007, ambos a preços de 2007).

GRÁFICO 2 - EUA: MUDANÇA DA RENDA REAL DAS FAMÍLIAS POR QUINTIL E DOS 5\% MAIS RICOS 1966-2007

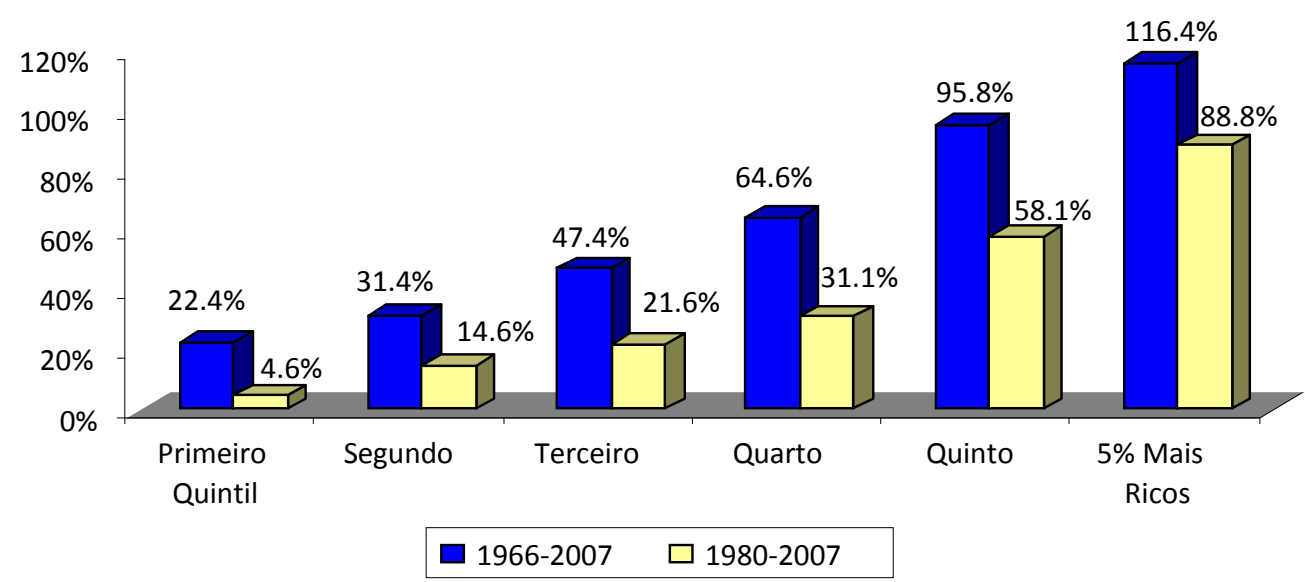

FONTE: U.S. Census Bureau, Historical Income Tables, Tabela F-3 (em dólares de 2007).

No período após a emergência do Governo Reagan, a renda dos mais pobres distanciou-se ainda mais da dos mais ricos (gráfico 2, acima). As causas dessa piora na distribuição de renda estão obviamente relacionadas com a emergência do modelo neoliberal. Primeiro, no rol das políticas neoliberais dos governos americanos desde Reagan, está o favorecimento tributário aos mais ricos com a justificativa de "estimular a poupança". Como resultado, considerando a renda disponível após os impostos, a diferença entre o porcentual da renda recebida pelos mais ricos em relação ao porcentual da renda recebida pelos mais pobres se ampliou de 1.13 para 3.25 vezes entre 1979 e 2005 (tabela 1, abaixo).

TABELA 1 - EUA: MUDANÇAS E PARTICIPAÇÃO NA RENDA REAL DISPONÍVEL POR QUINTIL DE RENDA

\begin{tabular}{l|c|c|c|c|cc}
\hline & Primeiro Quintil & Segundo & Terceiro & Quarto & Quinto & $\begin{array}{c}\mathbf{1} \% \\
\text { mais Rico }\end{array}$ \\
\hline \multicolumn{7}{c}{ Mudança na Renda Real das Famílias Após Impostos $\left(\Delta^{\%}\right)$} \\
\hline $1980-2005$ & 10.1 & 20.4 & 25.2 & 33.9 & 85.4 & 235.5 \\
\hline \multicolumn{7}{c}{ Participação na Renda $(\%)$} \\
2005
\end{tabular}

FONTE: Congressional Budget Office, Historical Effective Federal Tax Rates: 1979 to 2005, Tabela 1C, Dezembro de 2008. 
Se era para aumentar a poupança dos indivíduos, a redução de impostos para os mais ricos não funcionou, uma vez que a poupança pessoal despencou continuamente entre $1982 \mathrm{e}$ 2007. A poupança pessoal, que fora de $10 \%$ em 1982, caiu para menos de $1 \%$ como porcentual da renda das famílias em 2007 (gráfico 3, abaixo). Em 1936, Keynes já alertava para os equívocos do argumento da necessidade da desigualdade para aumento da taxa de poupança.

GRÁFICO 3 - EUA: TAXA DE POUPANÇA PESSOAL COMO PROPORÇÃO DA RENDA DISPONÍVEL - 1952-2008

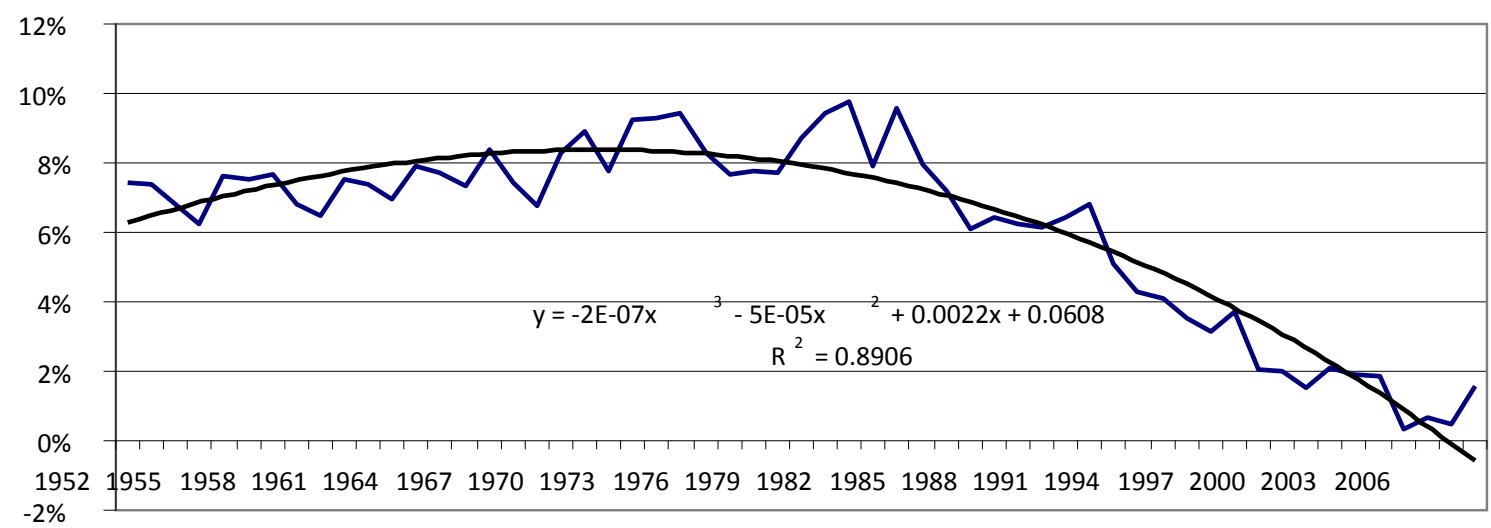

FONTE: Bureau of Economic Analysis, National Income and Product Accounts, Tabela 2.1, Personal Income and Its Disposition.

Por outro lado, a estagnação salarial teve grande responsabilidade no crescimento da desigualdade. Enquanto a mediana do salário recebido por trabalhadores acima de 16 anos mantivera-se abaixo ou ao redor de 12 dólares por hora (U\$11,81 em 1979 e U\$11,95 em 2007, ambos a preços de 2007) desde 1979 (Bureau of Labor Statistics, Report 1008, tabela 19), o produto por hora trabalhada multiplicou-se por um fator 6 no mesmo período (OECD Factbook 2008: Economic, Environmental and Social Statistics). É importante notar que a estagnação salarial pertencia à estratégia geral de abrir os mercados à competição predatória e à exigência de "ganhar eficiência" a qualquer custo para enfrentar os produtos importados ou ganhar mercados externos. De acordo com as preferências dos neoliberais, fazer os salários crescerem abaixo da produtividade do trabalho implica em um segundo benefício coletivo: a manutenção da inflação sob controle. ${ }^{10}$

\footnotetext{
${ }^{10}$ Veja o testemunho de Alan Greenspan dado ao Comitê do Orçamento do Senado Americano, em janeiro de 1997, no qual apresenta suas conviç̧ões neoliberais sobre o bom desempenho da economia sob o regime "job insecurity" (http://www.federalreserve.gov/boarddocs/testimony/1997/19970121.htm).
} 
Enquanto os salários permaneciam imóveis, os preços das casas disparavam com os incentivos e as bençãos do Federal Reserve de Alan Greenspan. A partir de 1995, a variação real dos preços das casas cresceu a uma média de 3,5\% nos anos posteriores, até seu primeiro colapso em 2007 (gráfico 4, abaixo). Nos 10 anos seguintes, a partir de 1996, o preço médio de casas nos EUA subiu de US\$140 mil para cerca de US\$248 mil. A relação "preço-renda" mostra que os preços dos imóveis estavam muito mais acelerados do que o crescimento da renda (gráfico 4, abaixo).

GRÁFICO 4 - EUA: VARIAÇÃO REAL DOS PREÇOS MEDIANOS DOS IMÓVEIS E RELAÇÃO PREÇO DOS IMÓVEIS-RENDA DISPONÍVEL (\%) - 1991-2007

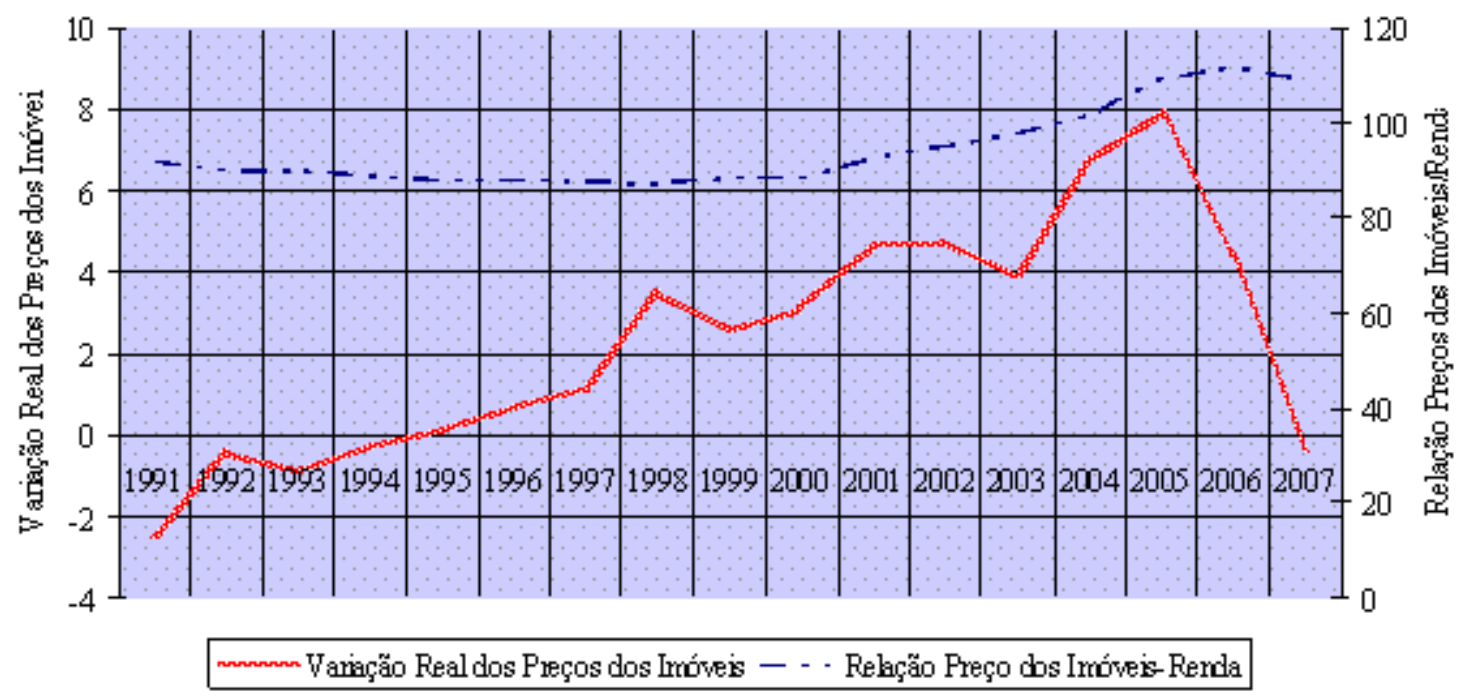

FONTE: OECD Economic Outlook, 2008, Tabelas 59 e 60.

GRÁFICO $5-$ EUA: RELAÇÃO DÍVIDA/RENDA DISPONÍVEL E DÍVIDAS HIPOTECÁRIAS/RENDA DISPONÍVEL (\%) - 1996-2007

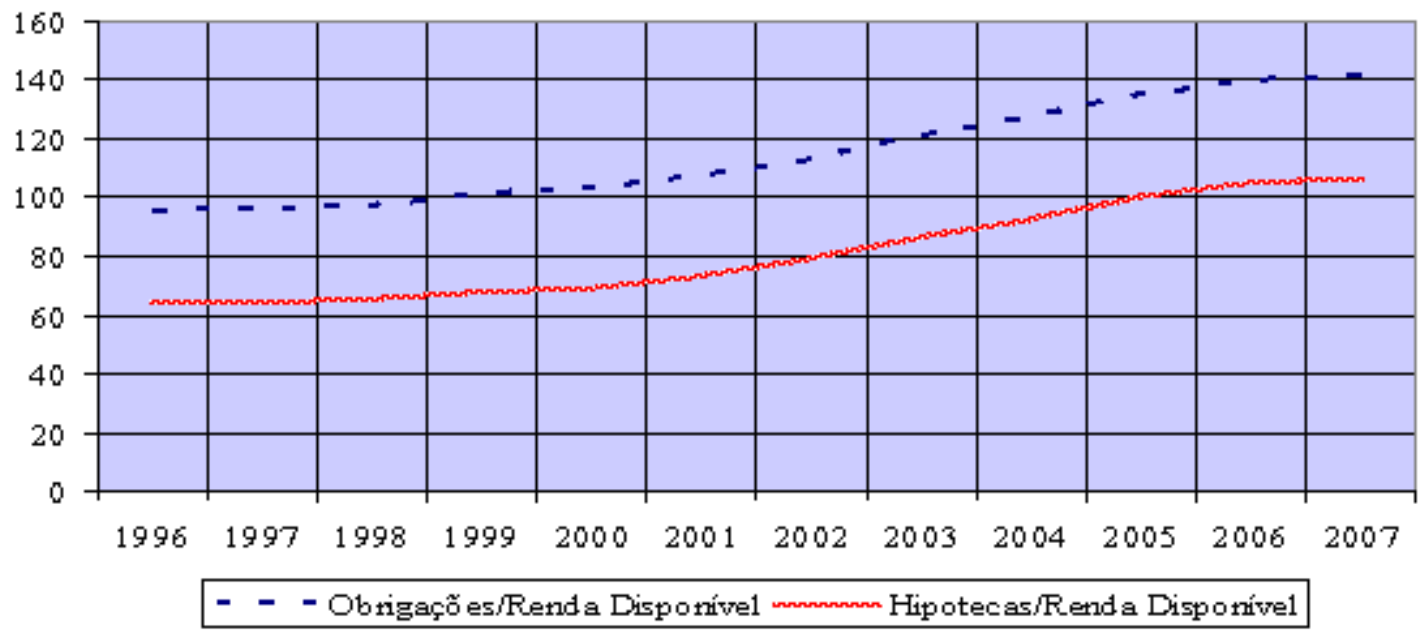

FONTE: OECD Economic Outlook, 2008, Tabela 58. 
Não há mais dúvidas, para a maioria dos economistas, de que a facilitação creditícia teve papel fundamental na supervalorização dos preços dos imóveis. As aspirações de ter uma casa própria - assim como um carro próprio, um diploma próprio etc. - foram não só financiadas, como instigadas pelo modelo "gera e distribui", por meio de inovações financeiras predatórias. Consequentemente, enquanto os salários estagnavam e crescia a distância entre ricos e pobres, crescia, concomitantemente, o endividamento dos mais pobres e o comprometimento da renda disponível com serviços financeiros das dívidas (gráficos 5, acima, e 6, abaixo). A vulnerabilidade financeira era, portanto, crescente, ainda que o modelo nutrisse a ilusão de alguns de que os riscos distribuídos haviam desaparecido ou, na conta neoliberal, de que os mercados sabiam melhor o que fazer com os riscos gerados. Na verdade, o risco sistêmico estava se avolumando com a distribuição setorial e espacial. Como se sabe, os indíviduos não conseguem assegurar-se apropriadamente no mercado contra riscos sistêmicos, de forma que a crise do modelo apenas a espalharia para setores e regiões longínquas - de onde foram geradas as dívidas - e seus compradores nem mesmo ficariam sabendo ao certo por que seus ativos perderam valor tão rapidamente.

GRÁFICO 6 - EUA: PARCELA DA RENDA DISPONÍVEL COMPROMETIDA COM O SERVIÇO DE DÍVIDAS FINANCEIRAS (\%) - (ÚLTIMO QUARTO DO ANO) 1980-2008

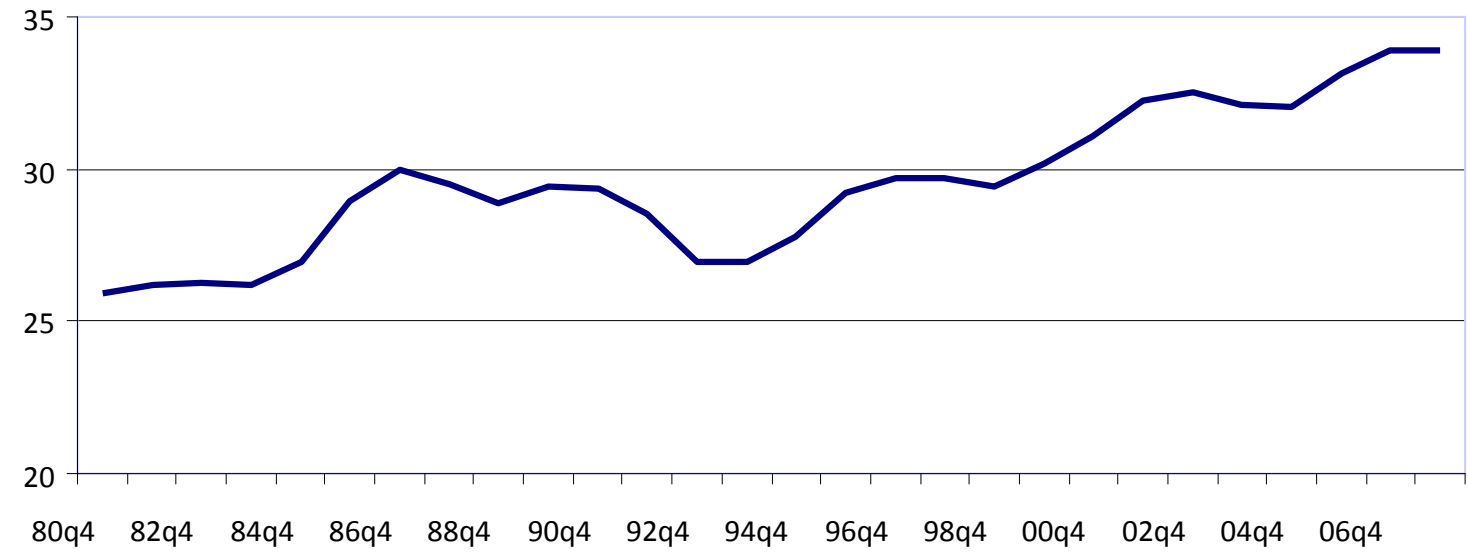

FONTE: The Federal Reserve Board.

O crescente endividamento das classes de mais baixa renda levaria necessariamente ao problema de pagamento dos débitos à medida que as rendas dessas classes estavam congeladas. Além disso, mesmo com as taxas de juros cadentes das décadas de 1990 e 2000 nos EUA, a combinação de redução salarial com ampliação do endividamento das famílias provocava uma crescente transferência de rendas para o setor financeiro. O Economic Outlook 80 de 2007 da OCDE mostra que os custos financeiros da dívida do quintil mais 
pobre dos americanos como proporção de sua renda é bem superior aos dos mais ricos, de forma que os mais pobres estavam mais vulneráveis a mudanças nas taxas de juros e/ou a perdas de renda. Isso significa, também, que a maior transferência de renda para o sistema financeiro se dava dos mais pobres para os credores. Enfim, o modelo "gera e distribui" reforçava os problemas de desigualdade mostrados acima, além de ampliar a vulnerabilidade do próprio sistema financeiro.

Por fim, ao longo da década de 1990 e 2000, a desregulamentação do sistema financeiro e as "vistas grossas" dos governos para as inovações predatórias permitiram aos bancos partir agressivamente para a concessão de crédito para os mais pobres de toda ordem (leasing de carros, hipotecas de casas, empréstimos para estudantes, seguros e cartões de crédito para financiar todo tipo de consumo). A securitização de dívidas e o modelo "gera e distribui" permitiam aos bancos disfarçar a insustentabilidade do sistema. O modelo continuava a se erigir nas pirâmides "Ponzi-Madoff" e empréstimos eram estendidos para cada vez mais arriscados devedores (exemplo, o subprime), de quem também eram cobradas as maiores taxas de retorno. Enquanto isso, autoridades americanas e reformadores do mercado enalteciam a "democratização" do crédito e o "bom" desempenho da economia baseada no "job insecurity" ". Para isso, inovações financeiras tinham de ser introduzidas constantemente e adicionadas à pilha de derivativos já existentes. A regulação, portanto, deveria ser leniente ao processo de "democratização" do crédito. A concessão de empréstimos ninja (non income, job and assets) exemplifica o tipo de inovações criadas para financiar a parcela superpobre dos desempregados. O público a que esses títulos se destinava sintetiza a natureza geral das políticas neoliberais adotadas.

Entretanto, a realidade da fragilidade financeira imposta por esse modelo aos mais pobres começou a bater às primeiras portas com a elevação das taxas de juros - que de meados de 2000 foram sendo reduzidas continuamente do patamar de $6 \%$ para atingir $1 \% \mathrm{em}$ meados de 2004 e, então, elevaram-se para 5,25\% em junho de $2006^{12}$. Essas taxas levaram dois anos para produzirem seus efeitos, uma vez que os empréstimos sub-prime eram realizados com cláusulas de reajuste bianual de juros. As taxas iniciais eram muito baixas para atrair os tomadores de crédito e, dessa forma, eram reajustadas dois anos depois. As taxas de atraso nos pagamentos rapidamente cresceram já em 2006, quando os reajustes vieram. As taxas de recuperação de casas pelos bancos credores seguiram a mesma tendência à medida

11 A referência é, novamente, o testemunho de Alan Greenspan, mencionado em nota anterior. http://www.federalreserve.gov/boarddocs/testimony/1997/19970121.htm.

${ }^{12}$ Ipeadata, Estados Unidos - taxa de juros básica - Federal Funds - fixada pelo FOMC (\% a.a.). 
que as hipotecas não eram pagas. Os preços das casas caíram e aumentaram as dificuldades das famílias em rolar suas dívidas, oferecendo como garantia suas próprias casas. ${ }^{13}$

Em seguida, o modelo ruiu e veio abaixo, como um castelo de cartas. Os bancos emprestadores amargaram grandes prejuízos nos últimos dois anos com o aumento da taxa de inadimplência e com a queda dos preços das casas que eram recuperadas por falta de pagamento. A quebradeira de bancos passou para toda a cadeia de agentes - seguradoras, fundos de pensão e de investimentos e outras instituições financeiras - que aplicavam recurso seus e de seus clientes no circuito financeiro do modelo "gera e distribui" e rapidamente espalhou seus efeitos para o resto do mundo. Os bancos centrais foram solicitados a conceder empréstimos emergenciais e até mesmo estatizar várias instituições financeiras. A retração do crédito que se seguiu, tem nutrido a fortíssima contração econômica recente. Empresas vem perdendo negócios no mundo todo e, quando não propõem reduções salariais, demitem, às dezenas de milhares, seus funcionários. $\mathrm{Na}$ crise, assim como na expansão anterior a ela, o modelo continua reforçando suas tendências ao desperdício de potencial produtivo (desemprego) e à ampliação da desigualdade de renda e de riqueza. É o efeito multiplicador operando às avessas.

Não há dúvidas de que as intervenções governamentais, na figura do emprestador de última instância associada ao déficit fiscal, fazem parte da estratégia de estabilização financeira e de recuperação da atividade produtiva. No entanto, a questão mais importante, como apresentada por Minsky (1986), não é se essas ações devem ou não ser tomadas. Elas devem, e em maior medida do que vem sendo feito. A questão fundamental é se a atuação do governo irá resolver os problemas que deram origem ao desenvolvimento da crise financeira. Se o argumento acima for convincente e os problemas de base forem em parte a desigualdade de renda e o desemprego, então a atuação que temos observado dos governos tende apenas a piorar as coisas. Primeiro, porque o socorro a instituições financeiras quebradas como Citibank, AIG, Bank of America, Lehman e outras pelo mundo, apenas resolve (ou minimiza) o problema do valor de mercado dessas instituições poluídas com os títulos “tóxicos" que elas mesmas criaram. Entretanto, essa ação agrava o problema da desigualdade, na medida em que os CEOs dessas companhias continuam fazendo suas altíssimas retiradas ao mesmo tempo em que demitem funcionários. Segundo, porque esses empréstimos de liquidez do governo

\footnotetext{
13 As referências são a palestra do presidente do FED Ben S. Bernanke na Columbia Business School, New York, em 5 de maio de 2008 e o relatório trimestral do First American CoreLogic do quarto trimestre de 2008, respectivamente: http://www.federalreserve.gov/newsevents/speech/Bernanke20080505a.htm\#ip1 http://www.loanperformance.com/riskmonitor/CMRM-Q4_final2_012909.pdf.
} 
não resolvem o problema de financiamento e de refinanciamento que se desenvolveu com a crise, uma vez que a taxa de inadimplência das famílias continua alta e em ascensão, as expectativas de recessão geral se agravam e as demissões se avolumam. Terceiro, porque os governos estão concedendo créditos a bancos e a firmas, seja para restaurar o crédito, seja para evitar demissões, sem que a sociedade tenha controle sobre a eficácia e a honestidade com que esses recursos serão utilizados. Não podemos esquecer que a atual crise tem um componente de corrupção, desonestidade e de falta de controle social das decisões públicas e privadas que são cruciais para a deslegitimação das atividades governamentais. Quarto, e relacionada a anterior, parte da sociedade pode entender que existem melhores opções de aplicação dos recursos públicos do que as que tem sido realizadas atualmente. Nos EUA, por exemplo, na mesma semana em que recebeu mais de U\$ 300 bilhões do governo em salvamento de seus títulos tóxicos, o Citigroup anunciou demissões de mais de 50 mil trabalhadores. Com esse mesmo dinheiro seria possível comprar as dívidas hipotecárias de mais de dois milhões de famílias - exatamente o número de casas retomadas pelos agentes financeiros dos credores sub-prime! $!^{14}$

\section{COMENTÁRIOS FINAIS}

Em resumo, enquanto os problemas centrais da crise, isto é, a desigualdade e o desemprego, não forem colocados como prioridade na intervenção do governo, as medidas monetárias e fiscais até agora tomadas apenas continuarão nutrindo o modelo anterior. Uma política de estabilização efetiva deveria, seguindo as linhas de Keynes e de Minsky, ter como norteadores três princípios simultaneamente: a) a geração de empregos, b) a redução da desigualdade e c) o controle social desses investimentos (a "socialização dos investimentos").

Nessa linha, o Brasil tem muito a aproveitar dessa crise para transformar seu modelo de desenvolvimento, uma vez que a crise enfraqueceu os argumentos neoliberais, quer a respeito dos exagerados benefícios que essa ideologia espera do setor privado, quer a respeito dos exagerados malefícios que imputa ao Estado. Contudo, ações de governos podem, sim, trazer consequências desastrosas para a economia, como provam os governos neoliberais desde o início dos anos 80 e as recentes intervenções do governo americano no meio da crise do ano passado. Em termos de política econômica, os princípios acima mencionados, entre outras coisas, podem ser assim operacionalizados: a) estabelecer um programa de geração de empregos com salários decentes para todos que queiram e possam trabalhar; b) orientar as

14 Para os dados, veja: http://www.newyorkfed.org/regional/subprime.html. No Brasil, além dos próprios bancos, o mais recente exemplo é a beneficiária de recursos públicos Embraer. 
políticas de investimentos do governo para setores de infraestrutura e de serviços públicos que geram benefícios particularmente para os mais pobres (educação, saúde, transporte público, assistência ao idoso e às crianças, assistência financeira a mães que cuidam de suas crianças e não podem, por isso, trabalhar, proteção sanitária e ambiental, lazer, aposentadorias etc.); e c) estabelecer mecanismos comunitários e classistas de controle desses investimentos e das políticas de governo como um todo (por exemplo, ampliação do Comitê de Política Monetária com assento de trabalhadores, de consumidores e de empresários para se decidir o nível das taxas de juros; organização de conselhos comunitários para deliberação e fiscalização sobre investimentos públicos e concessão de incentivos a setores empresariais etc.).

Enfim, mais do que requerer ajustes dos "erros" na condução da política monetária - do tipo, taxa de juros meio ponto percentual mais alta ou mais baixa -, ou ajustes marginais na condução da política fiscal - do tipo, privilegiar o investimento em detrimento dos gastos correntes -, a crise atual requer o reconhecimento de sua natureza endógena, ou seja, intrínseca ao funcionamento da economia capitalista que tende a usar insuficientemente seus recursos produtivos e a gerar desigualdade na distribuição de renda e de riqueza. A solução para esses problemas irá requerer a socialização das ações do Estado para torná-las benéficas para a maior parte dos trabalhadores - hoje, desempregados, endividados e ganhando salários insuficientes para proporcionar uma vida decente para suas respectivas famílias.

\section{REFERÊNCIAS}

CROTTY, J. The effects of increased product market competition and changes in financial markets on the performance of nonfinancial corporations in the neoliberal era. PERI Working Papers, Amherst, Massachusetts, 2002. Discussão.

KEYNES, J. M. The general theory of employment, interest, and money. San Diego: Harcourt, Brace, Jovanovich, 1964.

MINSKY, H. P. Stabilizing an unstable economy. New Haven: Yale University Press, 1986.

BRESSER-PEREIRA, L. C. The perverse logic of stagnation: debt, deficit, and inflation in Brazil. Journal of Post Keynesian Economics, v. 12, n. 4, p. 503-18, 1990. 
